\title{
On Supported Employment in the Russian Federation
}

\author{
Elena Blagireva \\ Russian State Specialized Academy of Arts \\ Moscow, Russia \\ blagireva@list.ru
}

\begin{abstract}
The paper evaluates the existing business environment in regard to exercising the rights of persons with special needs in the Russian Federation in the terms of their supported employment. The paper makes suggestion improving the quality of life of people who have disabilities and increasing their competitiveness in Russia.
\end{abstract}

Keywords-quality of life; education; items of cultural value and cultural benefits; accessibility; creation of special conditions; competitiveness; efficiency

\section{INTRODUCTION}

Delivery of the constitutional employment right to persons who have special needs in the Russian Federation presents the national issue.

The issue of employment support for such people remains one of the key challenges in the country. Even with the availability of job opportunities and creation of jobs (in line with the Federal Law "On social protection of persons with disabilities in the Russian Federation"), the employability of the disabled remains troublesome because available jobs do not factor in the specifics of the limited human activity of these persons [2].

Given that the level of employment of the disabled remains high, and on the assumption of high social proof of the activity pertaining to the assistance in the support employment, the government faces the challenge to improve the quality of employment of the disabled, bringing it to average performance across all groups of unemployed citizens in the country.

This calls for arrangement of special conditions for any person with disabilities, who is capable and willing to labor, under which such person can find his professional path and environment adjusted to one's special needs.

Pursuing the development of labor market and with the purpose to streamline the implementation of social plans providing privileges for the citizens with special needs, the Russian government guarantees employment conditions for such citizens. The actual labor potential of the disabled accounts for just under one million of the able-bodied population or $24 \%$. The Ministry of Labor and Social Protection of the Russian Federation has set the goal to double by the year 2020 the number of employed physically disabled people. The task is feasible through coordinated joint efforts of the government structures and employers, as a complex approach:
First, there is a draft bill on the delivery of employment assistance to the people with the special needs. Second, the authorities are working out the issue of workplace quotas for the disabled, and of special incentives for employers to create new jobs and retain the workplaces. Finally, special incentives are being drafted for employers providing jobs over quota for people with special needs.

These measures have been developed in a close cooperation with non-government organizations for the disabled.

By Russian law, there is a statutory alternative to the creation of workplace quotas, actively supported by employers today, providing any unemployed disabled with monthly welfare. As a way out of the current situation, the measures on creating specialized enterprises owned by public funds are often used.

Monitoring does not offer practical measures ensuring jobs for the disabled, yet, this is necessary to capture better the real extent of such persons' need in and demand for jobs, including specially outfitted (equipped) workplaces, to help the regional authorities and local governments to create adequate conditions for recruitment of the disabled in each region, involving both the state and non-state, private sectors.

The situation with the employment of the disabled in the regions of the Russian Federation is changing slowly and with difficulty. Amid relentless competition in the area of employment among the representatives of healthy population, jobs for the disabled are in most cases inaccessible. The demand for employment of the unoccupied disabled of the employable age remains high, even with the availability of adequate level of vocational education.

The recruitment of the disabled calls for crucial measures on their professional vocational rehabilitation, including suitable job searching and employment; additionally, a job allows for a decent standard of living of the disabled.

Many persons with the disabilities, who want to labor, stand no chance due to a host of obstructions. A person with disabilities starts to encounter difficulties at the stage of getting the desired profession. There is a sufficiently high demand among the disabled for vocational training - most of them demonstrate their willingness to complete professional training including higher learning [1]. The existing domestic practice of the so-called 'free placement' of graduates exacerbates the problem with a graduate's employment and physical disability, leading to a great deal of difficulty in job 
search by the disabled, as compared with other social categories. It needs to be underlined that the number of the disabled who want jobs is much greater than those who approach employment agencies.

The limited access to the transport infrastructure also makes a significant impact on the employment of the disabled relatively far from their residence. When getting a job they daily run into problems with unequipped public transportation, with the necessity in their assistance when moving. As a result, the general psychological stress of a disabled person force him either to look for another place or stay among the unoccupied.

Taking into account their social realm, the disabled are forced to give priority to self-employment or to accept a parttime job near where they live. Another impact of the insufficient professional assistance presents lower motivation and, as a result, difficulties with job selection.

Employment of the disabled is also complicated for reasons beyond their control. The reasons for this is the lack of the right amount of special jobs at enterprises, adapted for the activity of the disabled, or employers' disincentives to hire such citizens. Employers do not see in the disabled fullfledged personnel and regard their employment as a big problem, which requires, furthermore, substantial additional expenditure, which in turn impedes the implementation of measures under the individual rehabilitation and habilitation program.

Motivation of the disabled young people (of 16-35 years of age) considerably differ from that of the older age group generally by their desire to communicate with peers regardless of their physical condition. Again, getting to labour market, young people with disabilities run into a number of difficulties typical of all youth-no work experience and the need to create by an employer of special working conditions.

To remove the existing problem in the system of the people with disabilities employment, the government and regional authorities are taking strategies aimed at the development of inclusive labor market and working environment, ensuring the availability of employment for the disabled by providing them with jobs.

Accomplishment of the measures addressing the employment of the disabled, their adaptation and retaining also envisages and arranges their assistance.

The activity of socially oriented non-profit organizations in the area of employment assistance, adaptation and retaining with attraction of personal assistants, technical assistants is of a great importance for the development of inclusion in the field of employment of the persons with disabilities.

Enhancement of the efficiency of public organizations' support is achievable by means of rendering targeted employment assistance with attraction of personal assistants maintaining support of the disabled in their job search, recruitment and adaptation.
The community-focused non-profits, rendering additional targeted services of assistance in employment of the disabled, including the escort service for the disabled for the purposes of their recruitment, operate today in Moscow, Bryansk, in the Tambov, Nizhny Novgorod and Sverdlovsk regions, in the Stavropol and Krasnoyarsk Territories and in some other regions of the Russian Federation.

To improve effectiveness in the collaboration between the non-profits and government authorities in a number of the regions of the Russian Federation were launched the centers of assistance of the persons with disabilities for the purpose of their recruitment, securing their right in professional rehabilitation and integration into society, including career guidance, vocational training and job placement.

It should be noted that a number of the Russian regions have worked out and launched the mechanism of encouragement of employers creating jobs for recruitment of the disabled, including reimbursement of employers' costs resulting from the use of the persons with disabilities' labor (the Kaluga and Voronezh Regions, and the Republic of Tatarstan and other).

Accordingly, the system approach to creation of jobs for persons with disabilities suggests the presence of incentives for employers creating jobs for the disabled.

\section{THE RUSSIAN STATE SPECIALIZED ACADEMY OF ARTS}

We would like to speak about a unique educational institution, the Russian State Specialized Arts Academy (RGSAI). It is the only inclusive educational institution in the world. The Academy has established itself as a leader among Russian colleges. The Academy is an internationally competitive innovative educational institution both on the local and international levels:

- It has a flexible multi-level educational system, which includes professional orientation, pre-college preparation, bachelor's degree, specialist's degree, post-graduate course, professional assistance, internship assuring implementation of non-stop practice orientated educational course.

- A wide scope of pre-college preparation in different forms of its realization: applicants' preparation courses, improvement of artistry, etc., specially adapted programs for the people with special need.

- Flexible dynamic system for the non-stop process for the special needs people of different categories as an important factor of the personal and social growth of Russian citizens during their entire life, careful attention towards the problems in additional education; improvement of artistry for people with special needs .

- An effectiveness of interaction of this system with employers, provision of their involvement in every stage of preparation and the process of their professional competence. The result of this activity 
should be a highly professional level of preparation and guaranteed employment.

The Russian State Specialized Academy of Arts has created innovative scientific and applied complexes that guarantee an opportunity of employment [5]:

- There is a unique Opera House for the people with special needs.

- The Academy hosts annual festival "Viva Opera". Such operas as Dorgomyzhsky's "The Stone Guest", Tchaikovsky's "Iolanta" and Jacques Offenbach's "Un mari à la porte" are being performed here.

- There are two professional theatres for artists with hearing impairment "Nedoslov" and "Cinematograf" with performances tailored both for hearing and deaf spectators. 'Nedoslov' performs both in Russia and abroad.

- There is a unique center of the studies of the problems of rehabilitation of the special needs people by means of arts has been recreated. Special methodology has been created and developed in theatre, music, arts and design.

Considering the training and formation of talented youth with disabilities in further educational institutions, professional education and other institutions of learning in the field of culture and art to be the priority area for the art education development, the Russian State Specialized Academy of Arts has developed and implemented the programs of extended professional education (courses) for the teaching staff of child centers and for instructors of preprofessional, vocational and higher education dealing with children with disabilities and people with reduced capabilities $^{1}$ [5] [6].

In order to implement the program of continuing education and retraining of employees of cultural institutions, RGSAI has established the Institute for retraining of art, culture and tourism professionals (IPRIKT).

The Ministry of Culture of Russia has developed the model of inclusive artistic education in the Russian Federation.

The role of the coordinator for the creation and implementation of the system of inclusive artistic education in the Russian Federation was entrusted to the leading higher education institution in the area of inclusive artistic education the Russian State Specialized Academy of Arts.

The system of education in the field of culture presents one of the most essential constituents of the country's economy, as it forms the professional pool creating unique products. Our society should fully use the hidden potential of persons with disabilities and become richer and more diverse in its cultural display. This concept allows declaring that the

\footnotetext{
${ }^{1}$ Teachers of the Academy toured many regions of Russia with lectures, seminars and workshops under the program "Inclusive education of people with disabilities and limited health capacities in the sphere of culture and art".
}

social group of the disabled making its input can become a worthy resource for further development. This problem resolution requires, however, a special management approach and social technologies.

At the same time, should be admitted the insufficiency of social and economic research, interconnected and complementary by methodology and subject, in evaluation of the accessibility, the role of the disabled in national economy, of this social group's expectations and capabilities; although such research, in particular, could form a base for the development of mechanism of prompt standardization of such people's quality of life parameters, including those in the sphere of culture and education. In its turn, the development of living standards will make it possible to create a perfect mechanism for the society management and ensure a more accurate understanding of the results of managerial activity at all levels of authority.

One of the options to resolve the problem of employment of the disabled can be the model of inclusive education 'Art House' as an artistic creative complex, including an Opera House for blind or poor seeing people, a drama theatre for the deaf or poor hearing actors, a paramusical philharmonic with a chamber hall, picture gallery and art workshops. Such complex may become the model project, accumulating the experience of different cultural institutions of Russia in the area of rehabilitation of the people with special needs, as well as the sharing of such experience with other Russian regions. Such organization may present workshop for the people with special needs of artistic professions as well as their further growth in the area of culture and arts [6] [7].

\section{CONCLUSION}

Stated differently, the achievement of a higher level of social development largely depends on how adequately and timely the management system addresses social challenges. In this regard, the necessity of social and economic monitoring, which would show not just the material and technical (basic) willingness of culture to become accessible for the people with disabilities, but would also evaluate these persons' expectations and social health, regarding their capabilities in the cultural sphere, and in that social role that this group can assume in time, will be more and more topical.

\section{REFERENCES}

[1] Federal Law No. 273-FZ "On Education in the Russian Federation" as of December 29, 2012.

[2] Federal Law No. 181-FZ " On the social protection of disabled people in the Russian Federation" as of November 24, 1995.

[3] Legal reference system "Consultant Plus". Retrieved from http://www.consultant.ru.

[4] E. N. Blagireva, O. A. Blinov, O. S. Rudakova, Interactive Methods in Educational Process. Work book. - M.: "NAUCHNAYA BIBLIOTEKA" publishing house. 2014.

[5] Integrated action plan for the period of 2015/2020 on conditioning education of children and adults with disabilities in the sphere of art.

[6] Activity Plan for the period of 2015/2017 on improving conditions for people with disabilities and restricted mobility to participate in public cultural life. 
[7] Minutes of the Meeting No. 12 of the Presidential Commission of the Russian Federation on People with Disabilities, as of November 25, 2015. 